\title{
Reusability of $\mathrm{Ni}_{2} \mathrm{Fe}_{3}$ Metal Catalyst for Upgrading Pyrolyzed Bio-Oil from Cellulose
}

\author{
Siyi LI and Jeffrey S. CROSS
}

Energy Science and Engineering, Department of Transdisciplinary Science and Engineering, Tokyo Institute of Technology, 2-12-1, Ookayama, Meguro, Tokyo 152-8552, Japan

\begin{abstract}
Recyclable catalysts are desperately needed for upgrading pyrolyzed bio-oil which is produced from biomass conversion in order to reduce cost and protect the environment. However, most catalysts used for producing bio-oil from the pyrolysis of biomass cannot be recycled, leading to costly catalyst regeneration or waste if disposed of. In this study, $\mathrm{Ni}_{2} \mathrm{Fe}_{3}$ has been chosen as the model catalyst to test the recyclable property of the metal cluster catalyst system. Cellulose is used as the biomass model reactant. The results from pyrolysis experiments and GC-MS show that the catalytic property of $\mathrm{Ni}_{2} \mathrm{Fe}_{3}$ remains constant even after repeated experiments. From the analysis of bio-oil by GC-MS, the catalyst even shows slightly better performance with repeated use due to the pyrolytic interaction with cellulose during the experiment.
\end{abstract}

\section{Introduction}

Recyclable catalysts are attracting greater attention today due to increasing needs for greater cost-effectiveness of chemical transformations and overall productivity. Furthermore, recyclable catalysts also minimize environmental impact, ultimately contributing considerably to sustainable chemistry. Indeed, catalyst recycling fits the "principles of green chemistry" (Clark 1999; Anastas and Kirchhoff 2002; Poliakoff et al., 2002; Horvath and Anastas 2007). Furthermore, the demand for useful homogeneous catalysts continues to increase every day due to the better activity and stability (Cornils et al., 2017). Until now, various techniques and methods were developed. For instance, putting the immobilized catalyst precursor onto a support material, then the catalyst can be quantitatively separated by filtration and recycled (Müller, et al., 2005; Song et al., 2006). However, to date, only a few percentages of products are produced by homogeneous catalysis, especially for producing bio-oil. Most researchers use supported-catalysts to produce biooil or upgraded bio-oil, where the catalyst catalyzes the bio-oil vapors. For example, Lee's group used Ni-based catalysts (Ni, Ni-Mo, and Mg-Ni-Mo)/activated charcoal (AC) to understand their catalytic effect on the yield and the quality of upgraded liquid fuel in supercritical ethanol (Lee et al., 2019); Meunier's group put Pt, Pd and Rh on alumina and used this catalyst to reformed some model compounds in order to investigate how they influence the products (Rioche et al., 2005); Basagiannis's group found that a catalyst consisting of $\mathrm{Ru}(5 \%)$ dispersed on $15 \%$ $\mathrm{MgO} / \mathrm{Al}_{2} \mathrm{O}_{3}$ carrier exhibits high activity and selectivity in producing hydrogen (Basagiannis and Verykios 2007). However, all of this supported-catalyst will lose activity after the experiment, they cannot be recycled. There is a clear need to design and produce easily recoverable and recyclable homogenous catalysts. Based on our knowledge and research activity, the cluster catalyst is an ideal choice.

A cluster is an ensemble of bound atoms or molecules that are intermediate in size between a molecule and a bulk solid. The metal cluster can also be used as a catalyst (such as $\mathrm{Ru}_{3}(\mathrm{CO})_{12}$, Au cluster, etc.); they sometimes also bound to some other metal or cluster (Oguri et al., 2013). The cluster catalyst has extraordinary property, the absence of large bulk phases leads to a high surface-to-volume ratio, which is advantageous in any catalyst application as this maximizes the reaction rate per unit amount of catalyst material, which also minimizes cost. Other types of Nickel-based catalysts have been extensively employed in the industrial process of steam reforming because of their high activity and low cost (Cheng et al., 2017; Ji et al., 2017). Besides, the metal cluster catalyst has better physical properties, like large specific heat capacity and high thermal conductivity coefficient.

Considering potential large-scale applications, catalysts made of cheap and earth-abundant elements are crucial for economically viable energy conversion processes. Instead of using rare earth or expensive metals, it is better to focus on making catalysts with nickel and iron in order to build a new type of re-useable catalyticcluster.

In this study, cellulose was chosen as the feed for pyrolysis, because it is the major component of biomass and often used as a model compound. Then, the $\mathrm{Ni}_{2} \mathrm{Fe}_{3}$ cluster catalyst (based on our group previous result) will be used for testing the recyclable property based on our previous test. The final goal of this study is to investigate the recyclable property of metal cluster catalysts in order to test its economic feasibility. 


\section{Experimental Method}

\subsection{Catalyst preparation and separation}

The biomass feed, $38 \mu \mathrm{m}$ powdered cellulose was brought from Wako Pure Chemical Industries, and cellulose was directly used without any modification.

The $\mathrm{Ni}_{2} \mathrm{Fe}_{3}$ catalyst was prepared by the sol-gel method, which produced a cluster structure (De and Tapfer, 1996; Jayaprakash et al., 2015). The chemicals were ethylene glycol, $\mathrm{Ni}\left(\mathrm{NO}_{3}\right)_{2} \cdot 6 \mathrm{H}_{2} \mathrm{O}, \mathrm{Fe}\left(\mathrm{NO}_{3}\right)_{3} \cdot 9 \mathrm{H}_{2} \mathrm{O}$ and citric acid, which also purchased from Wako Company (Osaka, Japan). The mol ratio between metal ion $(\mathrm{Fe}, \mathrm{Ni})$ and citric acid was 1:1.2. The preparation of catalysts was performed at room temperatures following: $14.5 \mathrm{~g} \mathrm{Fe}\left(\mathrm{NO}_{3}\right)_{3} \cdot 9 \mathrm{H}_{2} \mathrm{O}$ and $6.97 \mathrm{~g} \mathrm{Ni}\left(\mathrm{NO}_{3}\right)_{2} \cdot 6 \mathrm{H}_{2} \mathrm{O}$ was dissolved in $40 \mathrm{ml}$ distilled water and stirred for 4.5 hours. Then $6 \mathrm{ml}$ of ethylene glycol and $13.4 \mathrm{~g}$ citric acid were added to the beaker. The transparent solution was stirred for 20 hours in order to prepare a uniform chemical solution. The transparent sol was dried at $110^{\circ} \mathrm{C}$ in an oven for 26 hours. Next, using a furnace, it was calcined at $700^{\circ} \mathrm{C}$ for $6 \mathrm{~h}$ to burn off hydrocarbons in flowing $95 \%$ $\mathrm{N}_{2}, 5 \% \mathrm{H}_{2}$ gas. Finally, the catalysts were crushed into powder using a mortar and pestle.

After each experiment, the catalyst would be separated with char by physical method, using a magnetic and aluminum plate. Then using this catalyst in the next experiment.

\subsection{Pyrolysis method}

Cellulose $(5 \mathrm{~g})$ was loaded in a $50 \mathrm{~mm}$ diameter quartz tube reactor mixed with the catalyst $(5 \mathrm{~g})$. The entire system was purged with flowing nitrogen gas for $4 \mathrm{~min}$ in order to expel all air. Afterward, the reactor was heated to the set temperature $\left(450^{\circ} \mathrm{C}\right)$ with a heating rate of $45^{\circ} \mathrm{C} / \mathrm{min}$ in flowing $\mathrm{N}_{2}$ gas. Nitrogen gas carried the pyrolyzed vapors from the reactor to the condenser.

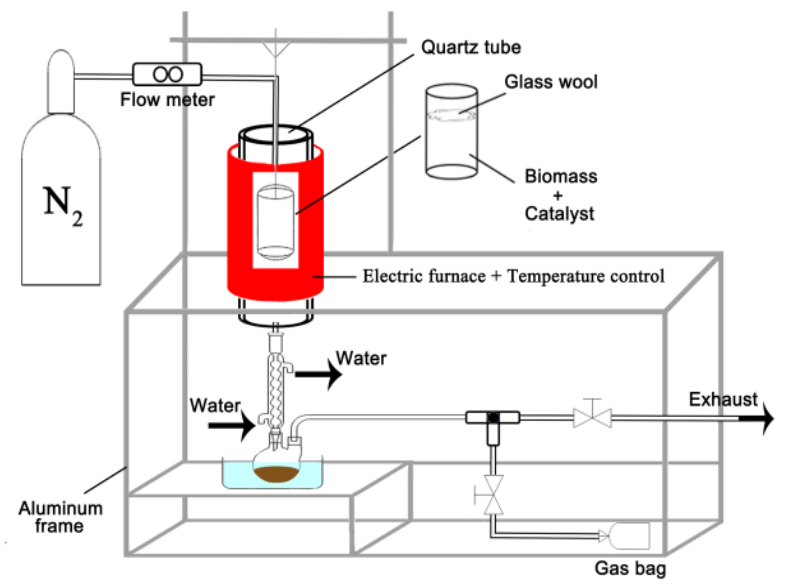

Figure 1. Experimental set-up for pyrolysis reation

The vapors were condensed using cold water in the condenser. The bio-oil was collected and analyzed by GCMS. The char and catalysts were separate, finally using this catalyst to repeat the above experiment, multiple times. The amount of bio-oil and char \& coke were weighed, and then the amount of gas was calculated by subtracting the amount of bio-oil and char \& coke from the initial feed (Figure 1).

\subsection{XRD, BET and SEM test}

XRD analysis of catalysts was conducted by X-ray Diffractometer (Mini Flex 600, Tokyo, Japan). 45 kV and $15 \mathrm{~mA}$ were used for the X-ray tube operation. The scan range ( 2 theta) of the XRD pattern was collected from $5^{\circ}$ to $90^{\circ}$ using filtered $\mathrm{Cu}$ radiation.

Specific surface areas were measured using the Brunauer-Emmett-Teller method with $\mathrm{N}_{2}$ (BEL SORP mini; Bel Japan Inc., Tokyo, Japan).

Images of catalysts were obtained by a scanning electron microscope (VE-9800, Tokyo, Japan) operated at $10 \mathrm{kV}$. The glass slide washed by ethanol to get clear images. Then the samples were loaded and dried on a copper grid (carbon-coated) before the test.

\subsection{GC-MS analysis method}

In order to identify compounds and analyze the composition of the bio-oil samples, GC-MS equipment was used to analyze bio-oil samples. The analysis was performed on a GC-2010 Plus equipped with a GC-MSQP2010 SE mass-detector made by Shimadzu Corporation (Tokyo, Japan). The column type was Stabilwax-DA $30 \mathrm{~m} \times 0.25 \mathrm{~mm}, 0.25 \mu \mathrm{m}$ diameter (Bellefonte, U.S). The analysis was run with a $10: 1$ split entry. The oven temperature was held at $40^{\circ} \mathrm{C}$ for $5 \mathrm{~min}$ and then ramped to $50^{\circ} \mathrm{C}$ at $1{ }^{\circ} \mathrm{C} / \mathrm{min}$. Next, it was ramped to $130^{\circ} \mathrm{C}$ at $2^{\circ} \mathrm{C} / \mathrm{min}$. Finally, the temperature was ramped to $260^{\circ} \mathrm{C}$ at $4^{\circ} \mathrm{C} / \mathrm{min}$ and held for $10 \mathrm{~min}$. The compounds were identified by comparing the mass spectra to NIST 11 MS library of compounds using the GC-MS software. A similarity threshold of over 80 was used to identify the compounds. All GC-MS experiments were conducted in duplicates, and the standard deviations were calculated.

\section{Results and Discussion}

\subsection{XRD and SEM analysis}

$\mathrm{X}$-ray diffraction patterns of all catalysts powder samples are shown in Figure 2. The first time represented the catalyst after the first experiment; the second time represented the catalyst after the second experiment (the same condition as the first experiment, the catalyst was used again after separation.) Figure 2 indicated that the XRD pattern agreed well with each other, and after comparing the used catalyst and unused catalyst showed the catalyst XRD pattern was unchanged during pyrolysis experiments and the catalyst can be recycled. Meanwhile, there were not any spurious diffraction 


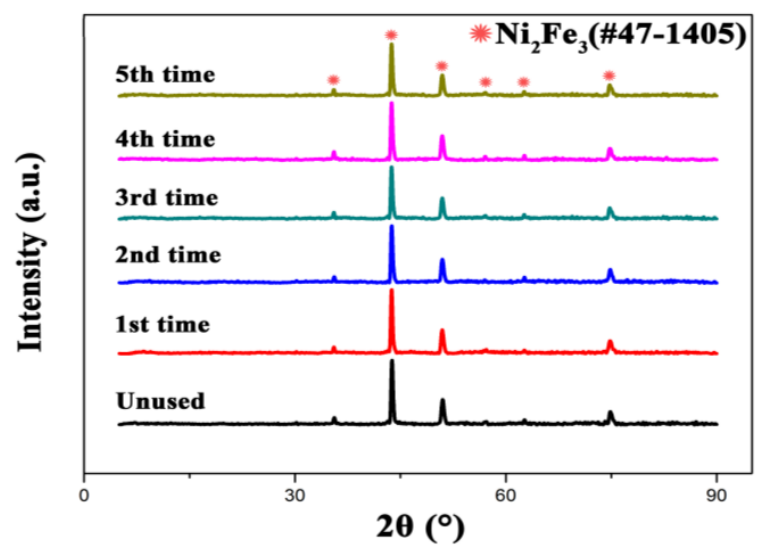

Figure 2. XRD patterns of unused and used catalysts.

peaks observed in the patterns, indicating no other impurity component and the sol-gel method was reliable for producing cluster structures. It should be noted that previous literature on the synthesis of bimetallic catalysts $(\mathrm{Ni}, \mathrm{Fe})$ only exhibited a single peak indicating the formation of a Ni-Fe solid solution (Nie, de Souza et al. 2014). The intensity of XRD peaks of the sample in Figure 2 reflected that the formed particles were crystalline and broad diffraction peaks indicated very small size crystallites.

The SEM images are shown in Figure 3, were of a typical particle with an uneven surface. A powder-like structure usually exhibited better catalytic properties as indicated previously (Yao et al., 2014). From the images,

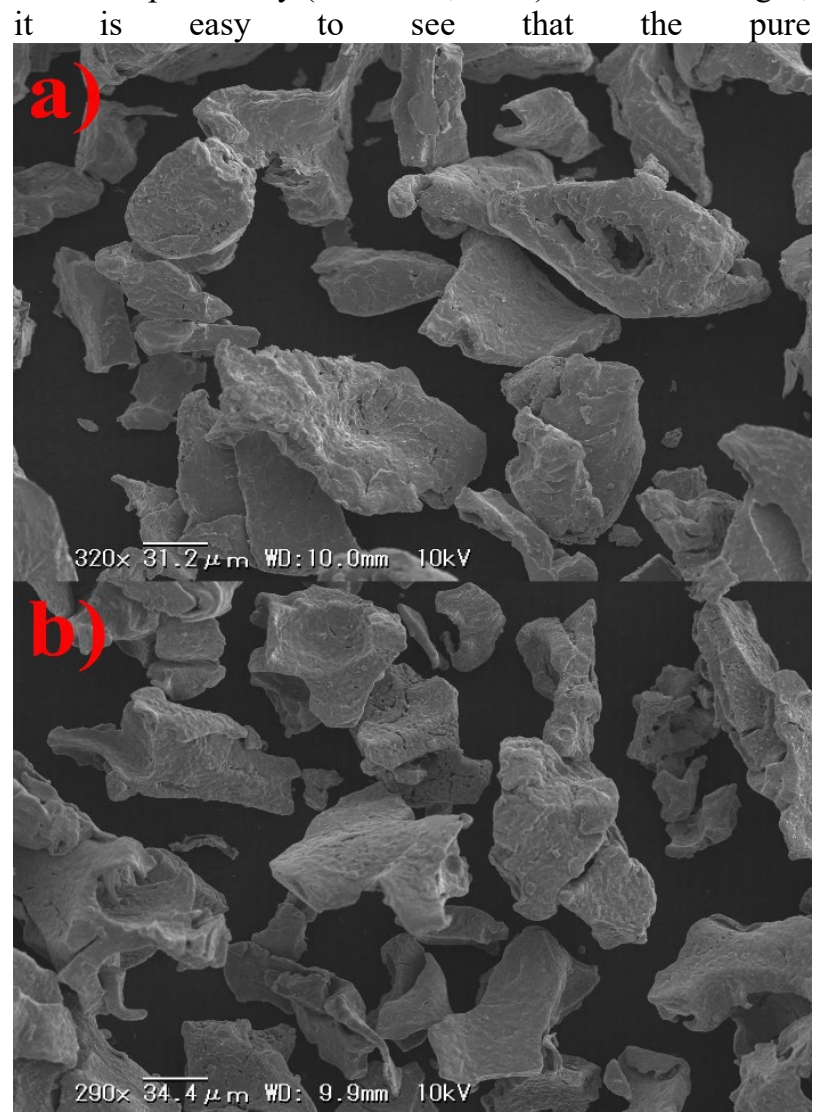

Figure 3. SEM images of a) unused and b) used (after 5 experiments) catalyst particles

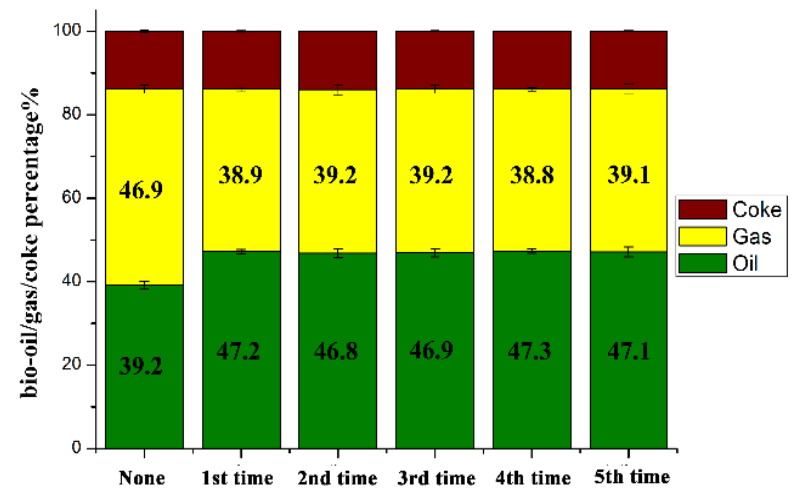

Figure 4. Bio-oil, gas and char\&coke yields from pyrolysis of cellulose without and with recycled catalyst

metal clusters did not have a large surface area due to consisting of many small clusters. BET results confirmed that the surface area was relatively small, only $\sim 2 \mathrm{~m}^{2} / \mathrm{g}$. Additionally, the particle size was the same after the experiment, which means the catalyst particles did not change, corresponding to XRD results.

\subsection{Pyrolysis Results}

\subsubsection{Yield results of pyrolysis}

The catalysts were mixed with the cellulose directly. The bio-oil and char \& coke were weighed, and yields were calculated after each pyrolysis experiment. Figure 4 shows the bio-oil mass yields of the different experiment time. The gas yield was calculated by subtracting the mass of bio-oil and char \& coke from the initial mass of cellulose. Each experiment was conducted more than one time to measure the repeatability.

The bio-oil yield from uncatalyzed cellulose pyrolysis was $39.2 \%$ and had a standard deviation of $0.8 \%$. The yield with the catalyst for the first experiment was $47.2 \%$, and $46.8 \%$ for the second experiment, $46.9 \%$ for the third experiment, $47.3 \%$ for the fourth experiment and $47.1 \%$ for the fifth experiment. From the results, it was obvious that the used catalysts can still improve the yield of bio-oil, which is an important property, because other catalysts have show decreased bio-oil yields, like ZSM-5, $\mathrm{ZrO}_{2} \& \mathrm{TiO}_{2}$, and silica (Stefanidis et al., 2014; Xia et al., 2015; Behrens et al., 2017).

The reason for the bio-oil yield increase was due to the difference in specific heat capacity and thermal conductivity coefficient. Specific heat capacity was the amount of heat energy required to raise the temperature of a substance per unit and the thermal conductivity coefficient indicates the rate of heat transfer. The specific heat capacity was $0.38 \mathrm{kcal} / \mathrm{kg} . \mathrm{k}$ for cellulose, 0.11 kcal/kg.k for Ni, 0.11 kcal $/ \mathrm{kg} . \mathrm{k}$ for Fe (ToolBox, website), respectively, which means no matter composition of nickel and iron both can increase its temperature quickly, the heated metal can help transfer heat uniformly to the cellulose. The thermal conductivity coefficients are (Madelung and White 1991) (see Table 1), $0.23 \mathrm{~W} / \mathrm{m} . \mathrm{K}$ for cellulose, $73.3 \mathrm{~W} / \mathrm{m} . \mathrm{K}$ for Ni, $61.6 \mathrm{~W} / \mathrm{m} . \mathrm{K}$ for $\mathrm{Fe}$ and were used estimate 
Table 1. Specific heat capacity and thermal conductivity coefficients for cellulose, Ni metal, Fe metal and cellulose with $\mathrm{NiFe}$ catalyst (SHC represents specific heat capacity, (kJ/kg.k); HCC represents thermal conductivity coefficient(W/m. $\left.{ }^{\circ} \mathrm{C}\right)$ ) $\bar{X}=\frac{x 1 f r 1+x 2 f r 2}{2}, \bar{X}$ used to define the mix thermal conductivity coefficient compound of cellulose and $\mathrm{Ni}_{2} \mathrm{Fe}_{3}, \mathrm{X}$ represents the thermal conductivity coefficient of compounds, fr represents the ratio of compounds

\begin{tabular}{|c|c|c|c|c|}
\hline & $\begin{array}{c}\text { SHC } \\
\text { (kcal/kg.k) }\end{array}$ & $\begin{array}{c}\mathrm{HCC}\left(200^{\circ} \mathrm{C}\right) \\
(\mathrm{W} / \mathrm{m} . \mathrm{K})\end{array}$ & $\begin{array}{c}\mathrm{HCC}\left(300^{\circ} \mathrm{C}\right) \\
(\mathrm{W} / \mathrm{m} . \mathrm{K})\end{array}$ & $\begin{array}{c}\mathrm{HCC}\left(400^{\circ} \mathrm{C}\right) \\
(\mathrm{W} / \mathrm{m} . \mathrm{K})\end{array}$ \\
\hline Cellulose & 0.38 & 0.23 & & \\
\hline $\mathrm{Ni}$ & 0.11 & 73.3 & 64.0 & 59.3 \\
\hline $\mathrm{Fe}$ & 0.11 & 61.6 & 54.7 & 48.9 \\
\hline Cellulose $+\mathrm{Ni}_{2} \mathrm{Fe}_{3}$ & & 12.48 & & \\
\hline
\end{tabular}

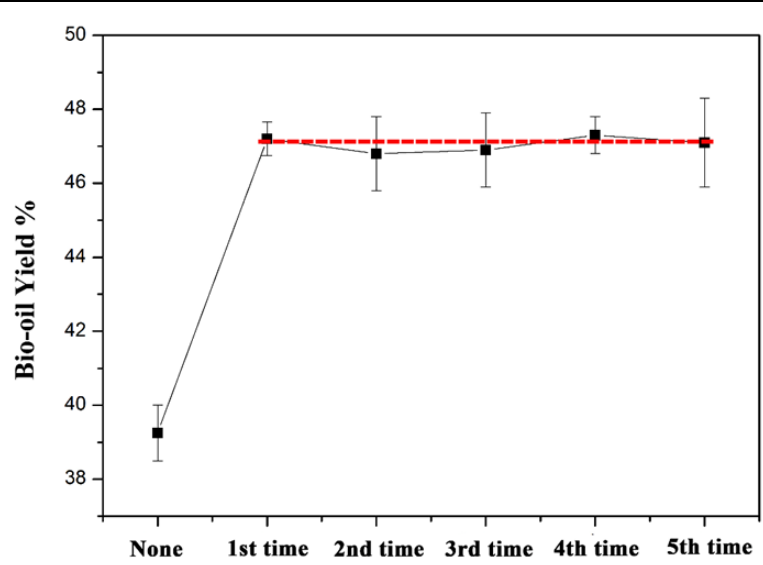

Figure 5.The relationship between bio-oil yield without catalyst and with catalyst for repeated use up to 5 times

for calculation of $22.2 \mathrm{~W} / \mathrm{m} . \mathrm{K}$ for the $\mathrm{Ni}_{2} \mathrm{Fe}_{3}$ catalyst mixed with cellulose. Ni and Fe coefficients are nearly 120 times higher than that of cellulose, which means for cellulose without a metallic catalyst being present, heat transfer from the reactor furnace to the cellulose is relatively poor. Some hot spots may develop in the cellulose during experiments, which tends to produce gas. However, after adding a $\mathrm{NiFe}$ catalyst, the thermal conductivity coefficient is enhanced 50 times, which can help transfer heat well and cause a uniform temperature profile which increases the bio-oil yield (see Table 1). There maybe some additional reactions that occur during the experiment that also enhance the yield, which will be investigated in future work

From Figure 5, it appears that the yield of bio-oil did not change, which means the NiFe metal cluster catalyst did not lose activity after experiments. It was a very important property for the catalyst if the catalyst can be recycled and costs can be minimized while improving reaction efficiency can be achieved due to reduced need to replace the catalyst.

\subsubsection{GC-MS results of cellulose results}

In order to know the composition of the bio-oils, the GCMS equipment was used for analyzing all the bio-oil samples. The results of the identified peaks are presented below in Table 2 . On average, $3 \%$ of the peaks were unidentified. Because the pyrolysis of cellulose resulted in hundreds of compounds, it was hard to list all of them. The compounds were classified into different groups based on their functional group. These groups were classified as acids, alcohols, furans, esters, hydrocarbons
(HC), ketones, phenols, sugars, and others. Table 2 shows the major product of uncatalyzed cellulose were sugars $(47.7 \%)$, ketone $(17.5 \%)$, furans $(20.7 \%)$, and acids $(4.9 \%)$. In this study, phenolic compounds were also found in uncatalyzed cellulose pyrolysis bio-oil, which is the same as other researcher's results (Behrens et al., 2017). Other main components of the bio-oils derived from noncatalytic and catalytic pyrolysis of cellulose were in good agreement with the literature results (Fabbri et al., 2007; Lu et al., 2011; Xia et al., 2015).

In order to investigate if the property of catalyst would change or not after experiments, each group would be discussed in detail below. The data showed the relationship between the bio-oil component and the number of experiments in Figure 6 (based on averaged data).

First of all, in Table 2, the data indicated that hydrocarbon (HC) was formed, which is an excellent component to improve the quality of bio-oil although the ratio is only $1 \%$.

Secondly, all catalysts reduced acid and sugar composition which is a favorable property. Acids reduced the $\mathrm{pH}$ value of bio-oil, corroding common metals such as aluminum, mild steel, brass and so on. So it had an adverse effect on the quality of bio-oil. Reducing sugar can improve the quality of bio-oil due to their large oxygen content, the results agreed well with other studies that sugar was possible to be removed by catalysts (Wang et al., 2016; Behrens et al., 2017). Figure 6 showed the relationship between several experiments and the composition of bio-oil. It is clear that the NiFe metal cluster catalyst still works well after repeated experiments. Reduced sugar percentage from $47.7 \%$ to $30.5 \%$, acid from $5 \%$ to $2.5 \%$. Furthermore, the property of the catalyst showed a slight improvement after the first time experiment, similar to other group's results (Liu et al., 2019). After mixing used catalysts and bio-char, they obtained better results.

Third, Figure 6 showed that catalysts lead to an increase in furan and ketone percentage. The reason why we focused on ketone content was that many methods can change the ketone to hydrocarbon compounds to improve the quality of bio-oil as the chemical reaction advance (King et al., 2015; Mehta et al., 2015; Ly et al., 2017). So it is a favorable result for the bio-oil composition to have increased ketone concentration. Increased furan concentration is also good for bio-oil, since it can improve the combustion value. 
Table 2 Composition of cellulose pyrolysis products without catalyst versus number of repeated catalyst experiments (peak area \% of identified peaks, hydrocarbon (HC) compounds, unidentifiable compounds were classified as others)

\begin{tabular}{cccccccccc}
\hline sample & Acid\% & Alcohol\% & Esters\% & Furans\% & Ketone\% & Phenols\% & Sugar\% & HC\% & Others\% \\
\hline None & $4.9 \pm 0.2$ & $2.3 \pm 0.1$ & $2.0 \pm 0.1$ & $20.7 \pm 0.7$ & $17.5 \pm 2.6$ & $1.7 \pm 0.4$ & $47.7 \pm 0.2$ & 0 & $2.1 \pm 1.2$ \\
1st time & $3.0 \pm 0.3$ & $2.3 \pm 0.1$ & $2.4 \pm 0.2$ & $25.9 \pm 0.7$ & $29.7 \pm 0.8$ & $2.2 \pm 0.2$ & $31.5 \pm 0.6$ & $0.5 \pm 0.4$ & $2.4 \pm 0.4$ \\
2nd time & $2.1 \pm 0.2$ & $2.5 \pm 0.3$ & $3.4 \pm 0.9$ & $25.4 \pm 1.1$ & $29.9 \pm 1.1$ & $2.1 \pm 0.6$ & $30.0 \pm 0.3$ & $1.1 \pm 0.8$ & $3.5 \pm 0.4$ \\
3rd time & $2.0 \pm 0.1$ & $2.3 \pm 0.4$ & $3.8 \pm 0.2$ & $25.6 \pm .1 .1$ & $29.4 \pm 1.1$ & $2.5 \pm 1.0$ & $30.3 \pm 0.7$ & $1.4 \pm 0.1$ & $2.7 \pm 0.5$ \\
4th time & $1.9 \pm 0.1$ & $2.4 \pm 0.2$ & $3.2 \pm 0.4$ & $26.0 \pm 0.3$ & $29.6 \pm 0.4$ & $2.9 \pm 0.2$ & $30.7 \pm 0.3$ & $0.7 \pm 0.5$ & $2.6 \pm 0.3$ \\
5th time & $1.8 \pm 0.5$ & $2.4 \pm 0.7$ & $3.2 \pm 0.4$ & $25.7 \pm 1.2$ & $30.0 \pm 3.5$ & $2.6 \pm 0.4$ & $30.2 \pm 2.4$ & $1.1 \pm 0.8$ & $2.9 \pm 0.2$ \\
\hline
\end{tabular}

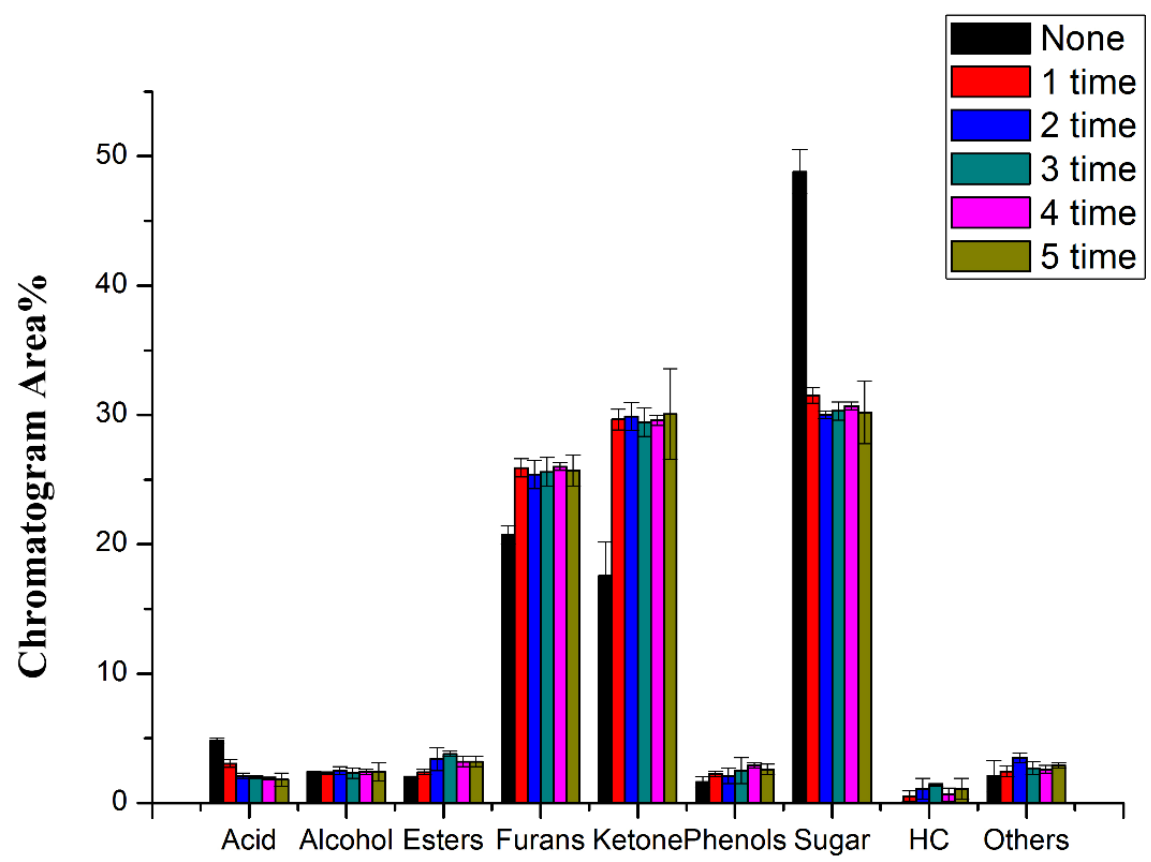

Organic composition of bio-oil product

Figure 6. Chemical relative compositions of the organic phase of bio-oil without catalyst and after repeated catalyst use up to 5 times

Finally, the catalyst did not affect the phenol, alcohol, and ester amounts. The phenol compounds are usually formed from secondary reactions of the cellulose vapors (Stefanidis, Kalogiannis et al. 2014; Wang, Ma et al. 2016), which is why it did not change a lot in this study. Based on the above analysis, the following reaction pathway is proposed. The cellulose decomposed into sugar first, and then the sugar decomposed further into acid, furan, and ketone compounds. The same mechanism has been proposed in our previous study ( $\mathrm{Li}$, Cheng et al. 2020). We believe this reaction sequence can help explain the composition of the pyrolyzed bio-oil and catalyst interaction.

\section{Conclusion}

The $\mathrm{Ni}_{2} \mathrm{Fe}_{3}$ cluster catalysts were prepared by the sol-gel method successfully and the recyclable property was tested. The results indicated a new potential type of stable recyclable catalyst can be used for pyrolysis and the yield of bio-oil and composition was also stable after repeated experiments. This $\mathrm{Ni}_{2} \mathrm{Fe}_{3}$ cluster catalyst also showed a different reaction pathway when compared to other supported catalysts in the literature, directly transferring heat to the biomass while catalyzing the vapors. Furthermore, this cluster catalyst can reduce catalyst costs due to its recyclability since it is easy to separate from char.

\section{Reference}

Anastas, P. T. and M. M. Kirchhoff; "Origins, Current Status, and Future Challenges of Green Chemistry," Acc. Chem. Res., 35, 686-694 (2002)

Basagiannis, A. C. and X. E. Verykios; "Steam Reforming of the Aqueous Fraction of Bio-oil over Structured $\mathrm{Ru} / \mathrm{MgO} / \mathrm{Al}_{2} \mathrm{O}_{3}$ Catalysts," Catal. Today, 127, 256-264 (2007)

Behrens, M., J. S. Cross, H. Akasaka and N. Ohtake; "A Study of Guaiacol, Cellulose, and Hinoki Wood Pyrolysis with Silica, $\mathrm{ZrO}_{2} \& \mathrm{TiO}_{2}$ and ZSM-5 Catalysts," J. Anal. Appl. Pyrolysis, 125, 178-184 (2017) 
Cheng, S. Y., L. Wei, J. Julson, K. Muthukumarappan and P. R. Kharel; "Upgrading Pyrolysis Bio-oil to Hydrocarbon Enriched Biofuel over Bifunctional FeNi/HZSM-5 Catalyst in Supercritical Methanol," Fuel Process. Technol., 167, 117-126 (2017)

Clark, J. H.; "Green Chemistry: Challenges and Opportunities," Green Chem., 1, 1-8 (1999)

Cornils, B., W. A. Herrmann and M. Beller; Applied Homogeneous Catalysis with Organometallic Compounds: A Comprehensive Handbook in Four Volumes. pp. 1-120, John Wiley \& Sons, Hoboken, U.S.A. (2017)

Fabbri, D., C. Torri and V. Baravelli; "Effect of Zeolites and Nanopowder Metal Oxides on the Distribution Ofchiral Anhydrosugars Evolved from Pyrolysis of Cellulose: An Analytical Study," J. Anal. Appl. Pyrolysis, 80, 24-29 (2007)

De, G. and L. Tapfer; "Formation of Copper and Silver Nanometer Dimension Clusters in Silica by the Sol-gel Process," Appl. Phys. Lett., 68, 3820 (1996)

Horvath, I. T. and P. T. Anastas; "Innovations and Green Chemistry," Chem. Rev., 107, 2169-2173 (2007)

Jayaprakash, J., N. Srinivasan, P. Chandrasekaran and E. K. Girija; "Synthesis and Characterization of Cluster of Grapes Like Pure and Zinc-doped $\mathrm{CuO}$ Nanoparticles by Sol-gel Method," Spectrochim. Acta, Part A, 136, 18031806 (2015)

Ji, X., B. Liu, W. C. Ma, G. Y. Chen, B. B. Yan and Z. J. Cheng; "Effect of $\mathrm{MgO}$ Promoter on Ni-Mg/ZSM-5 Catalysts for Catalytic Pyrolysis of Lipid-Extracted Residue of Tribonema Minus," J. Anal. Appl. Pyrolysis, 123, 278-283 (2017)

King, A. E., T. J. Brooks, Y. H. Tian, E. R. Batista and A. D. Sutton; "Understanding Ketone Hydrodeoxygenation for the Production of Fuels and Feedstocks from Biomass," ACS Catal., 5, 1223-1226 (2015)

Lee, J. H., I. G. Lee, J. Y. Park and K. Y. Lee. "Efficient Upgrading of Pyrolysis Bio-oil over Ni-based Catalysts in Supercritical Ethanol," Fuel, 241, 207-217 (2019)

Liu, Q. C., Z. Xiong, S. S. A. Syed-Hassan, Z. T. Deng, X. Y. Zhao, S. Su, J. Xiang, Y. Wang and S. Hu; "Effect of the Pre-reforming by Fe/bio-char Catalyst on a TwoStage Catalytic Steam Reforming of Bio-oil." Fuel, 239, 282-289 (2019)

Ly, H. V., E. Galiwango, S. S. Kim, J. Kim, J. H. Choi, H. C. Woo and M. R. Othman; "Hydrodeoxygenation of 2Furyl Methyl Ketone as a Model Compound of Algal Saccharina Japonica bio-oil using iron phosphide catalyst," Chem. Eng. J., 317, 302-308 (2017)

Müller, C., M. G. Nijkamp and D. Vogt; "Continuous Homogeneous Catalysis," Eur. J. Inorg. Chem., 2005, 4011-4021 (2015)

Madelung, O. and G. K. White; Thermal Conductivity of Pure Metals And Alloys, Springer, New York, U.S.A. (1991)
Mehta, M., M. H. Holthausen, I. Mallov, M. Perez, Z. W. Qu, S. Grimme and D. W. Stephan; "Catalytic Ketone Hydrodeoxygenation Mediated by Highly Electrophilic Phosphonium Cations," Angew. Chem. Int. Ed., 54, 82508254 (2015)

Nie, L., P. M. de Souza, F. B. Noronha, W. An, T. Sooknoi and D. E. Resasco; "Selective Conversion of Mcresol to Toluene over Bimetallic Ni-Fe Catalysts," $J$. Mol. Catal. A: Chem., 388-389, 47-55 (2014)

Oguri, T., K. Shimamura, Y. Shibuta, F. Shimojo and S. Yamaguchi; "Ab Initio Molecular Dynamics Simulation of the Dissociation of Ethanol on a Nickel Cluster: Understanding the Initial Stage of Metal-Catalyzed Growth of Carbon Nanotubes," J. Phys. Chem. C, 117, 9983-9990 (2013)

Poliakoff, M., J. M. Fitzpatrick, T. R. Farren and P. T. Anastas; "Green Chemistry: Science and Politics of Change," Science, 297, 807-810 (2002)

Lu, Q., Z. Wang, C. Q. Dong, Z. F. Zhang, Y. Zhang, Y. P. Yang and X. F. Zhu; "Selective Fast Pyrolysis of Biomass Impregnated with $\mathrm{ZnCl}_{2}$ : Furfural Productiontogether with Acetic Acid and Activated Carbon as By-products," J. Anal. Appl. Pyrolysis, 91, 273-279 (2011)

Rioche, C., S. Kulkarni, F. C. Meunier, J. P. Breen and R. Burch; "Steam reforming of model compounds and fast pyrolysis bio-oil on supported noble metal catalysts." Appl. Catal. B, 61, 130-139 (2005)

Song, C. E., D. H. Kim and D. S. Choi; "Chiral Organometallic Catalysts in Confined Nanospaces: Significantly Enhanced Enantioselectivity and Stability," Eur. J. Inorg. Chem., 2006, 2927-2935 (2006)

Stefanidis, S. D., K. G. Kalogiannis, E. F. Iliopoulou, C. M. Michailof, P. A. Pilavachi and A. A. Lappas; "A Study of Lignocellulosic Biomass Pyrolysis via the Pyrolysis of Cellulose, Hemicellulose and Lignin," J. Anal. Appl. Pyrolysis, 105, 143-150 (2014)

Engineering ToolBox; Specific Heat of Some Metals, https://www.engineeringtoolbox.com/specific-heatmetals-d_152.html (2003) accessed on 26, May, 2019

Wang, Z., R. Ma, W.G. Lin and W. L. Song; "Pyrolysis of Cellulose under Catalysis of SAPO-34, ZSM-5, and Y Zeolite via the Py-GC/MS Method," Int. J. Green Energy, 13, 853-858 (2016)

Xia, H., X. Yan, S. Xu, L. Yang, Y. Ge, J. Wang and S. Zuo; "Effect of Zn/ZSM-5 and FePO4Catalysts on Cellulose Pyrolysis," J CHEM-NY, 2015, 1-11 (2015)

Yao, D. D., C. F. Wu, H. P. Yang, Q. Hu, M. A. Nahil, H. P. Chen and P. T. Williams; "Hydrogen Production from Catalytic Reforming of the Aqueous Fraction of Pyrolysis Bio-oil with Modified Ni-Al Catalysts," Int. J. Hydrogen Energy, 39, 14642-14652 (2014)

Li, S. Y., S. Cheng and J. S. Cross; "Homogeneous and Heterogeneous Catalysis Impact on Pyrolyzed Cellulose to Produce Bio-oil," Catalysts (2020) printing 